\section{Are the New Guidelines for the Use of Lipid-Lowering Agents Sound, and Should Their Adoption Be Encouraged?}

\section{THE "PRO" SIDE}

The American College of Cardiology/American Heart Association (ACC/AHA) 2013 guideline on the treatment of blood cholesterol to reduce atherosclerotic cardiovascular risk in adults $^{1}$ will, if followed, usher in an era of more effective, more efficient, and more rational pharmacotherapy for cardiovascular risk reduction.

For as long as elevated cholesterol has been recognized as a cardiovascular risk factor and drugs have been available to lower cholesterol, guidelines for their use have existed. ${ }^{2,3}$ The prevailing perspective has been based on the dogma that elevated cholesterol (especially low-density lipoprotein [LDL] cholesterol) causes atherosclerosis, and therefore that lowering it by any means (drugs or diet) reduces the risk of cardiac events. ${ }^{4}$ This simple "lipid hypothesis" is congruous with the blood pressure hypothesis of cardiovascular disease and has shaped a generation of clinicians' approach to risk reduction. Evidence to support the idea that "lower is better" has arisen to lend apparent support, ${ }^{5}$ and guidelines (based mainly on consensus) have proffered targets and threshold lipid values. ${ }^{6,7}$ However, the evidence to support this "targeted therapy" approach is purely observational, showing only a correlation between cholesterol values and cardiovascular risk. ${ }^{8}$ This correlation does not prove the lipid hypothesis any more than positive associations between C-reactive protein or homocysteine and cardiovascular risk proves their causal role. The trail of fallacies leading from association to perception of causation that has arisen from lipid studies is well described. ${ }^{9}$ The lipid hypothesis has also been weakened by the SEAS ${ }^{10}$ and ENHANCE ${ }^{11}$ trials of ezetimibe, and beliefs about the beneficial effects of high-density lipoprotein cholesterol are currently under siege. ${ }^{12}$

One inconvenient fact has always overshadowed the targeted approach: there have been no randomized controlled trials (RCTs) in which drug therapy was titrated to achieve particular lipid targets. ${ }^{1}$ Rather, nearly all RCTs have involved giving a fixed dose of study drug to defined patient groups. Such trials lend no support to the lipid hypothesis but do show that drugs, especially statins, can reduce cardiovascular risk. This "tailored therapy" approach has long been advocated on the basis of analyses showing greater net benefit and less overall drug exposure than the targeted approach. ${ }^{13-15}$

The ACC/AHA 2013 guideline resoundingly advocates the tailored therapy approach to cardiovascular risk reduction. ${ }^{1}$ This will be a major change for many clinicians but, compared with the targeted approach, is more likely to result in judicious use of statins in patients most likely to benefit, as well as reducing the cost, toxicity, and complexity of polytherapy and reducing the costs of repeated cholesterol level measurements, physician visits, and dosage adjustments.

The new guideline singles out statins as the most appropriate drug therapy as an adjunct to healthy lifestyle. ${ }^{1}$ It goes further by acknowledging RCT evidence that more statin is more effective than less statin, ${ }^{16}$ recommending "high-intensity" statin therapy for the highest-risk patients. This recommendation is rational. If it is followed, its effect will be to produce a gradient of fixed statin doses commensurate with individual cardiovascular risk. The guideline focuses on the following 4 patient populations: (1) patients who already have atherosclerotic heart disease (a well-studied population in which fixeddose statin is effective regardless of cholesterol levels); (2) patients with diabetes mellitus older than 40 years of age (for whom RCTs support use of fixed-dose $\operatorname{statin}^{17}$ ); (3) primary prevention patients with a 10 -year risk of atherosclerotic heart disease above $7.5 \%$ (another population with RCT evidence to support fixed-dose statin use, albeit with lower absolute chance of benefit than the first 2 groups $^{18}$ ); and (4) patients with profoundly elevated LDL cholesterol signifying familial hypercholesterolemia (based on observational evidence). These patients are readily identifiable in general practice, with many of them requiring no measurement of blood cholesterol (groups 1 and 2) or only an initial cholesterol measurement for risk stratification (group 3) or to detect familial hypercholesterolemia. In my view, the guideline does not go far enough to discourage repeat cholesterol measurement, despite its forthright predicate that no cholesterol goals are justified.

The new guideline introduces a new risk assessment tool, which is somewhat welcome because it is bolstered (relative to the Framingham tool) by recent observational evidence involving "nonHispanic Caucasian and African American" men and women. Contemporizing a cardiovascular risk tool temporally, geographically, and in relation to ethnicity is usually worthwhile. However, the new tool has been criticized for overestimating risk ${ }^{19}$ and driving increased statin use. ${ }^{20}$ Further research is required to optimize the new tool and determine 
which of the many available schemes has superior accuracy in which populations. Fortunately, acceptance of the new ACC/AHA risk calculator is not required for applying the guidelines.

For practical, evidence-based, patient-centred reasons, clinicians should become familiar with the new ACC/AHA guideline on the treatment of blood cholesterol to reduce atherosclerotic cardiovascular risk in adults and follow it whenever possible.

\section{References}

1. Stone NJ, Robinson J, Lichtenstein AH, Bairey Merz CN, Blum CB, Eckel $\mathrm{RH}$, et al. 2013 ACC/AHA guideline on the treatment of blood cholesterol to reduce atherosclerotic cardiovascular risk in adults: a report of the American College of Cardiology/American Heart Association Task Force on Practice Guidelines. Circulation. 2013 Nov 12 [Epub ahead of print]. DOI 10.1161/01.cir.0000437738.63853.7a/

2. Report of the National Cholesterol Education Program Expert Panel on Detection, Evaluation, and Treatment of High Blood Cholesterol in Adults. The Expert Panel. Arch Intern Med. 1988;148(1):36-69.

3. National Cholesterol Education Program. Second Report of the Expert Panel on Detection, Evaluation, and Treatment of High Blood Cholesterol in Adults (Adult Treatment Panel II). Circulation. 1994;89(3):1333-445.

4. Fodor JG, Frohlich JJ, Genest JJ Jr, McPherson PR. Recommendations for the management and treatment of dyslipidemia. Report of the Working Group on Hypercholesterolemia and Other Dyslipidemias. CMAJ. 2000;162(10):1441-7.

5. Baigent C, Keech A, Kearney PM, Blackwell L, Buck G, Pollicino C, et al.; Cholesterol Treatment Trialists' (CTT) Collaborators. Efficacy and safety of cholesterol-lowering treatment: prospective meta-analysis of data from 90,056 participants in 14 randomised trials of statins. Lancet. 2005;366(9493):1267-78. Errata in: Lancet. 2005;366(9494):1358; Lancet. 2008;371(9630):2084.

6. Anderson TJ, Grégoire J, Hegele RA, Couture P, Mancini GBJ, McPherson R, et al. 2012 update of the Canadian Cardiovascular Society guidelines for the diagnosis and treatment of dyslipidemia for the prevention of cardiovascular disease in the adult. Can J Cardiol. 2013;29(2):151-67.

7. Expert Panel on Detection, Evaluation, and Treatment of High Blood Cholesterol in Adults (Adult Treatment Panel III). Executive summary of the Third Report of the National Cholesterol Education Program (NCEP). JAMA. 2001;285(19):2486-97.

8. Verschuren WM, Jacobs DR, Bloemberg BP, Kromhout D, Menotti A, Aravanis C, et al. Serum total cholesterol and long-term coronary heart disease mortality in different cultures. Twenty-five-year follow-up of the seven countries study. JAMA. 1995;274(2):131-6.

9. Hayward RA, Hofer TP, Vijan S. Narrative review: lack of evidence for recommended low-density lipoprotein treatment targets: a solvable problem. Ann Intern Med. 2006;145(7):520-30.

10. Rossebø AB, Pedersen TR, Boman K, Brudi P, Chambers JB, Egstrup K, et al.; SEAS Investigators. Intensive lipid lowering with simvastatin and ezetimibe in aortic stenosis. N Engl J Med. 2008;359(13):1343-56.

11. Kastelein JJP, Akdim F, Stroes ESG, Zwinderman AH, Bots ML, Stalenhoef AFH, et al.; ENHANCE Investigators. Simvastatin with or without ezetimibe in familial hypercholesterolemia. N Engl J Med. 2008;358(14):1431-43.

12. Voight BF, Peloso GM, Orho-Melander M, Frikke-Schmidt R, Barbalic M, Jensen MK, et al. Plasma HDL cholesterol and risk of myocardial infarction: a mendelian randomisation study. Lancet. 2012;380(9841):572-80.

13. Hayward RA, Krumholz HM, Zulman DM, Timbie JW, Vijan S. Optimizing statin treatment for primary prevention of coronary artery disease. Ann Intern Med. 2010;152(2):69-77.

14. Shepherd J. Resource management in prevention of coronary heart disease: optimising prescription of lipid-lowering drugs. Lancet. 2002;359(9325): 2271-3.
15. Zulman DM, Vijan S, Omenn GS, Hayward RA. The relative merits of population-based and targeted prevention strategies. Milbank Q. 2008; 86(4):557-80.

16. Cholesterol Treatment Trialists' (CTT) Collaboration; Baigent C, Blackwell L, Emberson J, Holland LE, Reith C, et al. Efficacy and safety of more intensive lowering of LDL cholesterol: a meta-analysis of data from 170,000 participants in 26 randomised trials. Lancet. 2010;376(9753):1670-81.

17. Colhoun HM, Betteridge DJ, Durrington PN, Hitman GA, Neil HAW, Livingstone SJ, et al.; CARDS Investigators. Primary prevention of cardiovascular disease with atorvastatin in type 2 diabetes in the Collaborative Atorvastatin Diabetes Study (CARDS): multicentre randomised placebocontrolled trial. Lancet. 2004;364(9435):685-96.

18. Ridker PM, Danielson E, Fonseca FAH, Genest J, Gotto AM Jr., Kastelein JJP, et al.; JUPITER Study Group. Rosuvastatin to prevent vascular events in men and women with elevated C-reactive protein. $N$ Engl J Med. 2008;359(21):2195-207.

19. Kolata G. Risk calculator for cholesterol appears flawed. NYTimes 2013 Nov 19 [cited 2013 Nov 19]. Available from: www.nytimes.com/2013/ 11/18/health/risk-calculator-for-cholesterol-appears-flawed.html?_r=0

20. Ioannidis JPA. More than a billion people taking statins? Potential implications of the new cardiovascular guidelines. JAMA. 2014;311(5):463-4.

Peter Loewen, BSC(Pharm), ACPR, PharmD, FCSHP, RPh

Director, Doctor of Pharmacy Programs

Assistant Professor

Faculty of Pharmaceutical Sciences

The University of British Columbia

Vancouver, British Columbia

Dr Loewen is also a Pharmacotherapeutic Specialist (Medicine), Vancouver General Hospital, Vancouver, British Columbia.

Competing interests: None declared.

\section{THE "CON" SIDE}

When we teach pharmacy students, we tell them that they should follow national guideline recommendations when treating patients. We assume that, because several of the best experts in the field reviewed the literature in detail, discussed the data, and drew a number of evidence-based conclusions, they know the "truth", i.e., they know what is the best way to treat a patient with a specific medical condition. On this basis, we might assume, then, that similar conclusions will be drawn when the same set of evidence is reviewed by a different group of experts with similar expertise.

At the beginning of 2013, the Canadian Cardiovascular Society (CCS) Dyslipidemia Panel published its latest dyslipidemia guidelines. ${ }^{1}$ Later that year, the American College of Cardiology/American Heart Association (ACC/AHA) Task Force on Practice Guidelines issued its new version of the 
ACC/AHA guideline on the treatment of blood cholesterol. ${ }^{2}$ As would be expected, both the US and Canadian guidelines recommend the use of statin-based therapy in higher-risk individuals, i.e., those with established atherosclerosis, most individuals with diabetes mellitus, and those with low-density lipoprotein (LDL) cholesterol above $5 \mathrm{mmol} / \mathrm{L}$. Moreover, the CCS guidelines, like the ACC/AHA and the European recommendations, ${ }^{3}$ put statins at the cornerstone of therapy, alongside lifestyle modifications.

Surprisingly, however, the ACC/AHA and CCS guidelines differ in some aspects. First, in addition to recommending the use of statin-based therapy in higher-risk patients, the ACC/AHA guideline recommends statin therapy for most patients considered at low or moderate risk (estimated 10-year risk of atherosclerotic cardiovascular disease $\geq 7.5 \%){ }^{2}$ Although it has not been confirmed, we might assume that these guideline changes would most likely result in a greater number of patients being medically treated with statins. ${ }^{4}$ On the other hand, the CCS guideline includes the following list of conditions defined as representing high risk of ischemic cardiovascular disease: presence of clinical atherosclerosis or abdominal aortic aneurysm; adjusted Framingham risk score $\geq 20 \%$; diabetes for more than 15 years in patients older than 30 years of age; diabetes in any patient older than 40 years of age; presence of microvascular disease; presence of high-risk kidney disease (estimated glomerular filtration rate $[\mathrm{eGFR}] \leq 45 \mathrm{~mL} / \mathrm{min}$ per $1.73 \mathrm{~m}^{2}$ or albumin-creatinine ratio $\geq 30 \mathrm{mg} / \mathrm{mmol}$ or eGFR $\leq 60 \mathrm{~mL} / \mathrm{min}$ per $1.73 \mathrm{~m}^{2}$ combined with albumin-creatinine ratio $\geq 3$ $\mathrm{mg} / \mathrm{mmol}$ ); or high risk hypertension. ${ }^{1}$

Second, even though both panels recommended that therapy be initiated on the basis of a calculated cardiovascular risk, 2 different approaches are presented. As in previous CCS guidelines, the updated CCS guidelines advocate use of a modified Framingham risk score, ${ }^{1}$ whereas the ACC/AHA guideline recommends use of the new pooled cohort equations. ${ }^{2}$ Although this new risk engine may provide some benefits (because it is derived from several cohorts and measures the risk of hard cardiovascular end points), some are concerned that it may not have been validated properly and may therefore overestimate risk. ${ }^{5}$ On the other hand, the modified Framingham risk score also has its limitations, one of which is poor uptake by primary care clinicians, especially to guide therapies for primary prevention. ${ }^{6}$

Third, the use of LDL cholesterol targets in the management of dyslipidemia was dropped by the ACC/AHA guidelines for the following reasons: (1) clinical trials have not aimed at achieving specific levels of LDL cholesterol but rather have randomized patients to fixed-dose medication regimens and consequently, the optimal treatment targets are not known; (2) several trials of combination therapy have not reported improved event rates relative to statin therapy alone; and (3) it is not known what benefits would be derived from selecting one target over a higher one. Instead, a novel yet controversial approach to treatment according to the patient's risk phenotype is advocated, with statins of different potency to be prescribed according to the patient's risk assessment.

In the end, the ACC/AHA guidelines went for a simplified approach, with a tool that is not validated, in the hope of greater uptake of the guideline. As a result, a greater number of Americans are being treated with evidence-based therapy. ${ }^{2}$ In contrast, the CCS guidelines have taken a more conservative approach, electing to continue to support the concept of LDL cholesterol targets in view of cardiovascular risk calculated with a validated risk assessment tool that has been in longer use. ${ }^{1}$

As for the question at hand-whether the new guidelines for the use of lipid-lowering agents are sound and whether their adoption should be encouraged - a few considerations must be taken into account before electing to rigorously follow the CCS guidelines or, for that matter, the ACC/AHA, guideline: (1) there have been no randomized trials confirming that use of the modified Framingham risk score (or the pooled cohort equations) to guide therapy provides optimal outcomes; and (2) the risk categories used internationally (low risk $<10 \%$, intermediate risk $10 \%-19 \%$, high risk $\geq 20 \%$ ) are arbitrary and do not rest on scientific evidence. ${ }^{1}$

In conclusion, a guideline should be viewed simply as a framework to guide clinical decision-making. Regardless of the recommendations in any guideline, individual decisions should always be made with respect to the specific patient, especially in primary prevention, where additional conditions not taken into account in the risk assessment engines may significantly influence risk (e.g., inflammatory conditions, high-risk ethnic background, or extremes of cardiovascular risk factors) and should be considered in the decision-making process.,4 Moreover, we should always give consideration to the potential for cardiovascular risk reduction, adverse drug reactions, and drug-drug interactions, as well as to patient preferences, before initiating medical therapy, rather than systematically adopting a "one treatment fits all" approach.

\section{References}

1. Anderson TJ, Grégoire J, Hegele RA, Couture P, Mancini GBJ, McPherson R, et al. 2012 update of the Canadian Cardiovascular Society guidelines for the diagnosis and treatment of dyslipidemia for the prevention of cardiovascular disease in the adult. Can J Cardiol. 2013;29(2):151-67.

2. Stone NJ, Robinson J, Lichtenstein AH, Bairey Merz CN, Blum CB, Eckel $\mathrm{RH}$, et al. 2013 ACC/AHA guideline on the treatment of blood cholesterol to reduce atherosclerotic cardiovascular risk in adults: a report of the American College of Cardiology/American Heart Association Task Force on Practice Guidelines. Circulation 2013 Nov 12 [Epub ahead of print]. doi: 10.1161/01.cir.0000437738.63853.7a. 
3. European Association for Cardiovascular Prevention \& Rehabilitation; Reiner Z, Catapano AL, De Backer G, Graham I, Taskinen MR, Wiklund O, et al. ESC/EAS guidelines for the management of dyslipidaemias: the task force for the management of dyslipidaemias of the European Society of Cardiology (ESC) and the European Atherosclerosis Society (EAS). Eur Heart J. 2011;32(14):1769-818.

4. Anderson TJ, Grégoire J, Hegele RA, Couture P, Mancini GBJ, McPherson R, et al. Are the ACC/AHA guidelines on the treatment of blood cholesterol a game changer? A perspective from the Canadian Cardiovascular Society Dyslipidemia Panel. Can J Cardiol 2014;30(4):377-80.

5. Ridker PM, Cook NR. Statins: new American guidelines for prevention of cardiovascular disease. Lancet. 2013;382(9907):1762-5.

6. Shillinglaw B, Viera AJ, Edwards T, Simpson R, Sheridan SL. Use of global coronary heart disease risk assessment in practice: a cross-sectional survey of a sample of U.S. physicians. BMC Health Serv Res. 2012;12:20.
Chantal Pharand, BPharm, PharmD, BCPS

Vice-Dean, Undergraduate Studies

Faculty of Pharmacy

Université de Montréal

Montréal, Quebec

Dr Pharand is also a Clinical Pharmacist, Cardiovascular Risk Reduction Clinic, Hôpital du Sacré-Cœur de Montréal, Montréal, Quebec.

Competing interests: None declared.

\section{ON THE FRONT COVER}

\section{Seven Sisters, British Columbia}

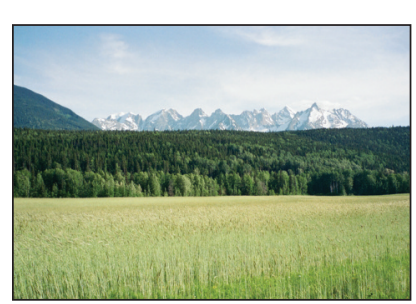

This photograph depicts a mountain range known as the Seven Sisters: seven peaks (four of which exceed an elevation of 2500 metres) in the Seven Sisters Provincial Park and Protected Area along the Yellowhead Highway, between Terrace and
Hazelton in northern British Columbia. The photographer was pharmacist Arden Barry, CSHP member and current President of the CSHP Alberta Branch. The image, obtained with a 35-mm camera, was taken in the summer of 2005 when Arden was working as a pharmacy student in Terrace.

The CJHP would be pleased to consider photographs featuring Canadian scenery taken by CSHP members for use on the front cover of the journal. If you would like to submit a photograph, please send an electronic copy (minimum resolution $300 \mathrm{dpi}$ ) to Colleen Drake at cdrake@cshp.ca. 